\title{
Career Satisfaction Survey of Young German Teachers in China
}

\author{
Weihua Du ${ }^{1}$, Jiahao Wang ${ }^{2}$, Zhongli $\mathrm{Hu}^{3, *}$ \\ ${ }^{1}$ German Dept. Guangdong University of Foreign Studies \\ ${ }^{2}$ German Dept. Guangdong University of Foreign Studies \\ ${ }^{3}$ German Dept. Guangdong University of Foreign Studies \\ *Corresponding author. Email: huzhongli@gdufs.edu.cn
}

\begin{abstract}
Young German teachers in China have a huge teaching load and are also under great pressure for personal development. How to analyse the opportunities and challenges they face and to investigate their job stress and satisfaction has become an issue that must be faced in the development of the German profession in China. This paper analyses the latest professional development of young German teachers in China through questionnaires and interviews, and propose reasonable suggestions for the development of young German teachers in China.
\end{abstract}

Keywords: Young teachers, German language, Career Satisfaction, China.

\section{INTRODUCTION}

In recent years, there have been numerous discussions about the career and living conditions of young teachers in colleges and universities, and the main issues generally explored are: high teaching workload, stressful research and economic conditions, low happiness index, and insufficient motivation for research among young teachers. As the core of university development, the career satisfaction of young teachers is related to their personal happiness and work motivation, which will thus have a non-negligible impact on teaching and research quality, university development and discipline construction. On this issue, a more comprehensive and detailed survey will help us grasp the career satisfaction status of young teachers more accurately and rationally, which in turn will help identify and target problems and promote the development of university education and research.

In June 2016, the first "National Forum on Young German Teachers' Development" was held at NankaiUniversity in Tianjin China. During this period, the survey team conducted a survey about career satisfaction in the form of a combination of interviews and questionnaires among more than one hundred young German teachers who attended the conference. The interviews were conducted with more than ten randomly selected participants and lasted about 30 minutes. The main purpose of the interviews was to make the questionnaire design more relevant and to provide a reference for the later analysis of the answers. The questionnaires were distributed online (via WeChat and email) and 98 valid responses were received. In the questionnaire, we conducted a detailed survey on the young German teachers' satisfaction with their current working conditions and their views on their career development prospects, and analysed the data.

\section{DESCRIPTION OF THE SAMPLE AND DATA}

Among the 98 young German teachers surveyed, there were 19 men and 79 women, with a male to female ratio of about 1:4. The age of the respondents was mostly distributed between 30 and 40 years old, accounting for $72.45 \%$ of the total number of respondents. As for the titles, only 12 of them were associate professors, accounting for $12.24 \%$, while the remaining 86 were lecturers. The percentage of associate professors among male teachers was $15.79 \%$, and the percentage was slightly lower among female teachers, at $11.39 \%$. The questionnaire provides a rough breakdown of the types of schools to which teachers belong, divided into five categories: comprehensive institutions, specialized foreign language institutions, polytechnics, financial institutions, and others. The top three in terms of numbers were $37.76 \%$ for comprehensive institutions, $29.59 \%$ for polytechnics and $18.37 \%$ for professional foreign language institutions. 
All questions on "satisfaction level" in this questionnaire are divided into four options: A. Very satisfied B. Somewhat satisfied C. Average D. Very dissatisfied. Meanwhile, in order to facilitate the observation of the overall level and data comparison, we assigned values to the options of some questions and calculated the weighted average. The rules for the assignment are as follows: for four options, options A, B, $\mathrm{C}$, and $\mathrm{D}$ are assigned $4,3,2$, and 1, respectively; for three options, A, B, and $\mathrm{C}$ are assigned 3, 2, and 1, respectively.

The study investigated the working conditions of young German teachers in terms of job stress, benefits, working environment, and social status, and asked teachers to answer questions about their overall feelings about their current jobs and whether they would leave their teaching positions if given the opportunity.

\section{CAREER DEVELOPMENT AND SELF- REALIZATION}

While the previous section summarized the evaluations of young German teachers about their current work situation, in this section we focus on the surveyed group's assessment of their career development prospects and potential for self-actualization. The topics in this section are roughly grouped into three modules: Evaluation and Promotion, Research and Further Training, and Current Status of the German Language Program, and we look at each of these modules in turn.

\subsection{Evaluation and Promotion Module}

The respondents with the title of lecturer generally did not feel optimistic about their chances of promotion, while the attitude of the group of associate professors who had already been promoted ranged from "average" to "relatively satisfied", probably due to their first promotion success. This may be due to the increased selfconfidence brought by the first promotion. However, both lecturers and associate professors are relatively dissatisfied with the current evaluation mechanism of the university, especially the lecturer group. In contrast, young teachers are slightly more satisfied that their efforts have been recognized by their superiors, but they are not satisfied either. On the whole, the road to the top is still full of obstacles and very difficult in the eyes of young German teachers.

\subsection{Research and Further Training Module}

The proportion of teachers who think that research and teaching do not interfere with each other is the highest in the comprehensive universities, at $21.36 \%$, while the proportion of teachers who feel that research is greatly affected by teaching is much lower than in the other two types of institutions, at $24.32 \%$. In contrast, close to $70 \%$ of teachers in professional foreign language institutions said that teaching has a strong influence on research. We assigned values of 3,2, and 1 to options A, $\mathrm{B}$, and $\mathrm{C}$, respectively, and calculated the mean value of this question to be 2.03 for comprehensive, 2.38 for scientific, and 2.56 for foreign language, which is consistent with intuitive feelings.

There are two possible explanations for this phenomenon: first, the foreign language institutions' emphasis on language proficiency determines that teachers' teaching work is more intensive than in other types of institutions, crowding out research time; the relative shortage of teachers in polytechnics (see the results of the survey on teachers below) may also lead to this situation; second, compared to foreign language institutions, foreign language subjects in comprehensive universities and polytechnics are often in a disadvantaged position, i.e., a good research environment, rather than teaching, is the primary factor affecting research efforts.

The largest proportion of the respondents was "not optimistic" (54.08\%), 26.53\% were relatively optimistic, and $18.37 \%$ thought that there were many obstacles to research, while only one person was very optimistic about the research prospect in his field. This proportion is similar among teachers with different titles and schools.

Finally, we asked teachers to write down the most important factors that hinder their research success, and the answers mentioned by two or more respondents (only some of the questionnaire completers answered this question) are summarized and tallied as follows.

Table 1 factors that hinder research

\begin{tabular}{|l|l|}
\hline $\begin{array}{l}\text { The most important factors that hinder } \\
\text { research }\end{array}$ & $\begin{array}{l}\text { Number } \\
\text { of people }\end{array}$ \\
\hline Lack of time and energy & 18 \\
\hline $\begin{array}{l}\text { Insufficient ability, lack of academic } \\
\text { guidance and training }\end{array}$ & 10 \\
\hline Poor research environment & 5 \\
\hline Not interested in research & 4 \\
\hline Lack of research materials & 4 \\
\hline Too few German-language journals & 3 \\
\hline $\begin{array}{l}\text { Unreasonable evaluation criteria for } \\
\text { research results }\end{array}$ & 3 \\
\hline $\begin{array}{l}\text { It is difficult to produce results in } \\
\text { small languages and the so-called } \\
\text { results are simply repeated }\end{array}$ & 3 \\
\hline
\end{tabular}

\subsection{Teacher Module}

Regardless of the type of institution, teachers who believe that there is no shortage of German teachers are in the minority, and a significant number of teachers believe that the lack of teachers is more serious, most notably in the polytechnics. In our interviews, we collected teachers' opinions about the reasons for the 
shortage of teachers and designed the following question in order to find out the number of teachers who agreed with each opinion.

The results show that the majority of the teachers who agreed with the statement that "schools are too demanding in terms of academic qualifications" believed that there was a shortage, while a small number of teachers believed that the number of teachers recruited by schools was too small or that the number of teachers interested in teaching German was low.

The data from this module concludes that most German teachers believe that the German program is relatively unappreciated in their schools and that there is a shortage of teachers, and that the primary reason for this shortage is the high academic standards for recruiting teachers. The combination of these factors has a negative impact on both teaching and research, and is detrimental to the development of the discipline, which in turn does not attract good teachers and students, leading to a vicious circle.

\section{CONCLUSION}

The large amount of teaching hours in the German program and the fact that most of the young teachers' time is spent teaching, but facing the pressure to promote their titles and university-wide dissertations, the average satisfaction of young German teachers with on-the-job training or further training opportunities is low, which indicates that young teachers who are in the period of building their teaching and research capacity and urgently need to "recharge" are in urgent need of teaching and research Training.

In terms of the importance that schools attach to the German language program, $44.9 \%$ said that they did not attach much importance to it, especially in science and technology institutions. The majority of the young teachers believe that the university needs to replenish its teaching staff, but the conditions for new teachers are not promising. Without new teachers, the number of hours of the existing teachers will be even higher, which leads to a lack of time and energy for teachers and further affects the research work, coupled with insufficient research training, poor research environment, few professional core journals, and difficulty in carrying out research in small languages, so most of the participants became a roadblock when promoting their titles. Personal development and professional development received a great hindrance.

Therefore, in order to develop the German major, we need to replenish more teachers, so that the existing teachers can have some time to carry out research work; at the same time, we need to strengthen the research ability of young German teachers through professional research training; the university should also provide certain conditions for research, change the current evaluation system for foreign language majors, and professional societies should publish more German professional journals.

\section{ACKNOWLEDGMENT}

[This thesis has got the Fond for 2020 Graduate Education Reform Research Project of Guangdong University of Foreign Studies "Promoting Chinese culture to go global and cultivating international German research talents" (20GWYJSXC-05)].

Du Weihua is Researcher at „Bilingual Cognition and Development Lab, Center for Linguistics and Applied Linguistics, GDUFS”, „Institut of Hermeneutics” and „Guangzhou Key Laboratory of Multilingual Intelligent Processing".

\section{REFERENCES}

[1] Jia Wenjian, Wei Yuqing, Research Report on Chinese German undergraduate major. Beijing: Foreign language Reaching and Research Press, 2011

[2] Pan Hong, Research on the influence of personal characteristics on College Teachers' professional satisfaction, in: Exploration of higher education, 2016(06).

[3] Ni Yonghong, A survey of College Teachers' professional satisfaction. Education and Career, 2015(01). 